\title{
INTER-LEARNER COMMUNICATION AND COLLABORATIVE LEARNING AS QUALITY CRITERIA OF DISTANCE VOCATIONAL EDUCATION AND TRAINING
}

\author{
Anastasia Batsila[anabtilse@gmail.com], Hellenic Open University [bttps://wmw.eap.gr/en/], Patras, Greece
}

\begin{abstract}
Distance web-based VET is nowadays of utmost importance for the EU. But, its special characteristics create doubts, as far as its quality is concerned, so research in this field is essential. According to the theoretical background, teaching methods and specifically, inter-learner communication and collaborative learning, are related to quality assurance. However, they are not always included in quality criteria nor is their use widespread in Greek distance VET. The aim of the research was to compare learner views with EU policy on the inclusion of inter-learner communication and collaborative learning in quality criteria. A qualitative research design was used to investigate EU quality assurance policy and frameworks. According to the findings, interlearner communication is included in seven EU quality assurance frameworks, while collaborative learning in five of them. Learners have the same opinion about collaborative learning, but interlearner communication is not as widely accepted as it is by EU organizations. However, from both perspectives, there is a stronger preference for distance inter-learner communication.
\end{abstract}

\begin{abstract}
Greek

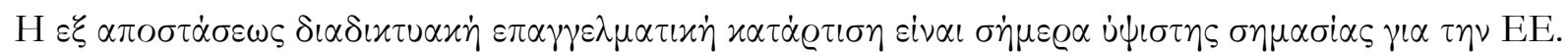

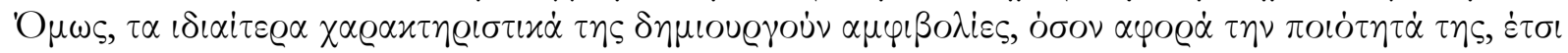



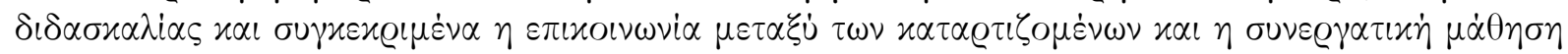

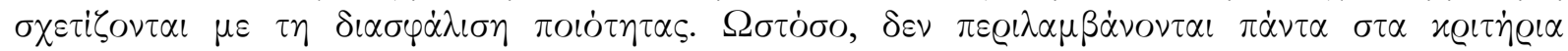



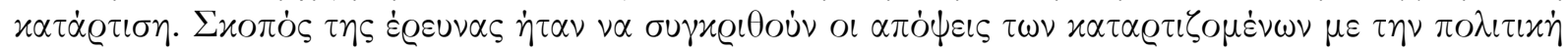



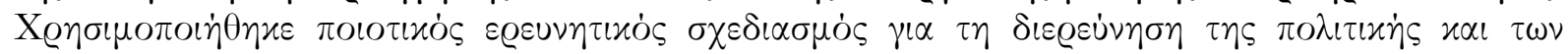

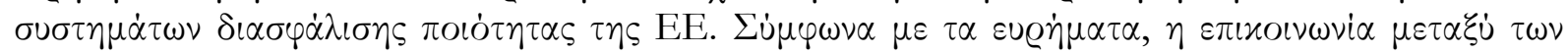



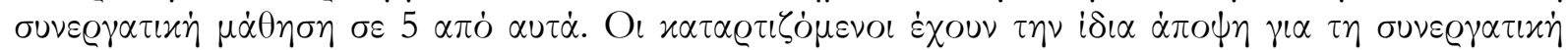

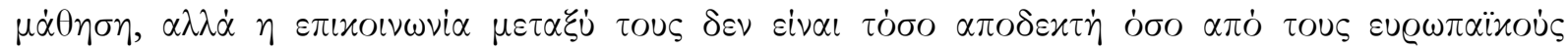

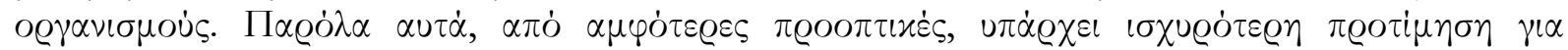



Keywords: distance web-based education, vocational education and training, quality assurance, communication, collaborative learning

\section{Introduction}

It is often argued that research needs to connect policy with practice, in order to improve the results of educational processes (Letherby \& Bywaters, 2007). The research presented in this article aimed at comparing both dimensions; the European Union (EU) policy with learners' views on the actual educational processes. The focus was on distance web-based initial and continuing vocational education and training (VET), which refers to courses or whole programs 
of study offered (exclusively or not) online. The basic characteristic of the field is that it offers skills necessary for a certain profession (Rogers, 2002). Distance web-based education (or e-learning) takes place online, with the help of virtual classes and digital media (Ossiannilsson, 2012). An example of distance web-based VET is MOOCs and CPD courses. The innovative online learning processes enable anyone to train and re-train anytime anywhere, fulfilling this way the growing need for VET (Gunawardena \& McIsaak, 2004).

This field is of utmost importance in a world of rapid technological progress and vast economic competition. Consequently, web-based VET is a top priority for the EU, something which justifies the strategic aim for the creation of a common quality assurance model (Collardyn \& Bjornavold, 2004). What needs to be assessed, however, is the suitability of these common quality criteria in every member-state. The importance of quality assurance in this particular field results also from the different nature of distance education. Questions arise regarding the quality of the teaching processes, due to the constant technological developments (Yeung, 2001). These issues, along with the high drop-out rates in distance web-based VET, make quality assurance vital (Rosewell \& Jansen, 2014). Furthermore, educational quality is given different and often opposing definitions, therefore there is no common agreement on how quality is assessed (Garrison, 2000). Due to the rapid technological evolution, quality criteria in the field of distance education should evolve and become up-to-date (Inglis, 2005). This means that it is necessary to research suitable quality criteria for this particular field (Zawacki-Richter, Baker, \& Vogt, 2009).

Teaching methods and processes are closely associated with quality (Simonson, Smaldino, \& Zvacek, 2015). As a result, relevant criteria are important in quality assurance systems. These two methods offer many advantages, so they are considered vital in distance education (Garrison, 2000). However, they are not always implemented in practice nor are they included in every quality assurance system. This leads to a need to research the inclusion of inter-learner communication and collaborative learning in quality assurance (Zawacki-Richter et al., 2009). Ultimately, what will be shown is, if their implementation is necessary and feasible in every webbased VET program of study.

\section{Quality Assurance in Web-based VET}

Quality in education denotes more than the typical definition we encounter in other fields (Ellis \& Calvo, 2007). What is central in education is improvement, which aims to fulfil learner needs (Lenert \& Janes, 2017). The most important part in educational quality assurance is learner experience, which means improved educational processes and results (Ehlers, 2004). Consequently, it is essential to create a quality assurance model which takes learners' opinions into consideration, not only during the assessment processes, but also during the creation of the specific criteria (Jung, 2012). And this is even more important, if we consider that most frameworks include criteria irrelevant to the teaching process (Baldwin \& Trespalacios, 2017). Moreover, most existing quality assurance frameworks in the field of distance education are designed for higher education institutions and universities, so their criteria are not suitable for web-based VET (Reis et al., 2008). As a result, it is necessary to create a quality assurance framework, whose criteria are suitable for all forms of web-based VET.

The same conclusion can be drawn from previous research, as the field is highly differentiated. Most studies investigate quality assurance in distance higher education and universities (Alexander \& Golja, 2007; Baldwin \& Trespalacios, 2017; Ellis \& Calvo, 2007; Lenert \& Janes, 2017; Merisotis \& Phipps, 2000; Ossiannilsson \& Landgren, 2012; Peres, Lima, \& Lima, 2014; Wang, 2014; Ward, Peters, \& Shelley, 2010). Fewer studies focus on distance VET (DeGennaro, 2010; Jacobs \& DeWet, 2013; Kidd \& Song, 2007; Mystakidis, Kostopoulos, \& Amanatidis, 2017; Read \& Rodrigo, 2014; Reis et al., 2008; Rosewell \& Jansen, 2014). Finally, a considerable 
number of previous studies refer to distance education in general (Claus \& Dooley, 2005; Ehlers, 2004; Inglis, 2005; Jung, 2012; Yeung, 2001).

\section{Quality Assurance in the European Union}

Distance web-based VET is nowadays very important, not only for the EU, but also worldwide, as it has become clear that it contributes to economic growth and technological progress (Official Journal of the EU, 2014). It is often argued in EU texts that retraining employees can lead to technological innovation (European Commission, 2018). This is the reason why it has been set as a strategic aim to increase the percentage of adults in Lifelong Learning by 2020. In order to achieve this, VET needs to become attractive to prospective learners, so quality assurance proves to be effective. Also, quality assurance is important for the EU, as it ensures validity of VET certification in every member-state (Yerevan Communiqué, 2015). For this reason, common quality criteria in every EU country are essential (Rosewell \& Jansen, 2014). Also, it is recognized that, in order to increase the number of learners, it is vital to create programs of study according to learner needs (Rosewell \& Jansen, 2014). Consequently, this should be the central component of EU quality assurance.

Previous research concerning VET quality assurance in the EU is of limited quantity. Studies on web-based VET compare European quality assurance frameworks, in order to create a common system (Ossiannilsson \& Landgren, 2012; Peres et al., 2014). However, most studies focus on the quality criteria of different EU models (Kear, Rosewell, \& Keith, 2012; Ossiannilsson, 2012; Read \& Rodrigo, 2014; Creelman, Ehlers, \& Ossiannilsson, 2014; Rosewell \& Jansen, 2014). Research in this field agrees that inter-learner communication and collaborative learning are included in EU quality assurance frameworks, considering the fact that they both benefit learners (Kear et al., 2012; Ossiannilsson, 2012; Read \& Rodrigo, 2014; Rosewell \& Jansen, 2014). This is one of the reasons why these frameworks are considered effective in improving distance VET (Ossiannilsson, 2012; Rosewell \& Jansen, 2014).

\section{Inter-learner Communication and Collaborative Learning as Quality Criteria}

There is no common agreement on specific criteria, suitable for modern web-based VET. Usually, we encounter two types of criteria; firstly, those related to the educational process (methods, learning material, assessment, communication) and secondly, those related to issues outside the educational process (policies, administration, finance, technical support) (Ellis \& Calvo, 2007). Also, very important for distance education is the assessment interactivity and adaptability to learners' needs (Ossiannilsson \& Landgren, 2012).

A great extent of previous research in this field focuses on quality criteria, proving their importance. A number of studies present the characteristics of a quality web-based course (Ehlers, 2004; Ellis \& Calvo, 2007; Jacobs \& DeWet, 2013; Jung, 2012; Kidd \& Song, 2007; Lenert \& Janes, 2017; Merisotis \& Phipps, 2000; Reis et al., 2008; Yeung, 2001). Baldwin and Trespalacios (2017) and Inglis (2005) present and compare different quality assurance frameworks. Most studies research a wide range of criteria. Only three of them focus on criteria related to the educational process, specifically communication and collaborative learning (Alexander \& Golja, 2007; Wang, 2014; Ward et al., 2010).

Most theorists argue that, in distance education, the teaching methods, not technology, play the decisive role in distance education (Claus \& Dooley, 2005). Consequently, quality does not depend on the medium, but on the actual process; the forms of teacher-learner and learnerlearner communication and the ways learners interact with the material (Simonson et al., 2015). Inter-learner communication is a central component of distance education (Moore, 2000). This 
idea stems from social theory, which argues that dialogue, collaboration and interaction with our social environment leads to effective learning (Vygotsky, 1978). Communication is even more important in distance education because of the physical distance between learners. Thus, according to the theory of transactional distance, when learners communicate and co-create knowledge, they feel close to each other, something which increases motivation and facilitates learning (Moore, 2013). Collaborative learning combines learner to learner communication with active participation, which is necessary for the acquisition of vocational skills (Rogers, 2002). Its purpose is the creation of a common result through dialogue, negotiation and feedback (Stacey, 1999).

Communication and collaborative learning prove to be invaluable for distance education (Alexander \& Golja, 2007; DeGennaro, 2010; Reis et al., 2008; Stacey, 1999; Wang, 2014). Specifically, learners can exchange knowledge and express themselves (Alexander \& Golja, 2007). Introvert learners can receive feedback, avoiding the embarrassment of communicating with the educator (Stacey, 1999). Furthermore, each learner feels responsible for a certain assignment and has a special role, something which gives them self-confidence and motivation (DeGennaro, 2010).

We conclude that communication and collaborative learning offer so many benefits that they are related to quality. Previous research has drawn the same conclusion (Alexander \& Golja, 2007; DeGennaro, 2010; Ehlers, 2004; Kidd \& Song, 2007; Wang, 2014; Ward et al., 2010). Moreover, previous studies argue that communication between learners should be included in quality criteria (Claus \& Dooley, 2005; Ossiannilsson \& Landgren, 2012; Yeung, 2001). The same was proven also for collaborative learning (Alexander \& Golja, 2007; Baldwin \& Trespalacios, 2017; Kear et al., 2012; Peres et al., 2014; Read \& Rodrigo, 2014; Ward et al., 2010). However, a small number of studies disagree as far as collaborative learning is concerned, creating thus the need for further research (Creelman et al., 2014; Lenert \& Janes, 2017; Merisotis \& Phipps, 2000).

In conclusion, previous research lacks studies on EU quality assurance frameworks in comparison to Greek learner views. There is a need to research quality assurance for web-based VET and, specifically, communication and collaborative learning as quality criteria. Relevant studies show contradictory results for collaborative learning, so further research is essential. Specifically, not many studies research in detail the suitability of these particular criteria in Greece. The research results could also reveal the importance and necessity of inter-learner communication and collaborative learning in web-based VET courses, for Greek learners.

\section{Research Aims and Research Questions}

The aims of the present research were: (a) to describe Greek learners' opinions about the inclusion of communication and collaborative learning in quality assurance criteria of distance web-based VET, (b) to compare these perceptions with EU policy for quality assurance in distance VET, as it follows from EU quality assurance frameworks. The research questions were:

- How do learners in Greece perceive the inclusion of inter-learner communication and collaborative learning in quality criteria for web-based VET?

- Do learner perceptions agree with EU quality assurance frameworks for web-based VET/ education?

- Is there a difference between inter-learner communication and collaborative learning, as far as their place in distance VET quality assurance is concerned? 


\section{Methodology}

\section{The Research Design}

Taking the research questions into consideration, the most suitable design was a mixed methods research. In order to investigate the EU policy, it was necessary to follow a qualitative design, which presents in detail a complicated issue (Creswell, 2012). Specifically, the relevant texts were investigated through content analysis to express the actual facts, but also the second level, the indirect aims which form part of the policy (Mayring, 2000). The second part of the research required a quantitative sample survey, as the aim was to describe learners' views (Creswell, 2012). Moreover, there was a need for a quantitative research on learners' thoughts and needs, as most previous studies follow qualitative methods to investigate them.

In order to answer the second research question, it was necessary to compare and contrast qualitative and quantitative data. Research on a practical level (educational process) should inform policy (quality assurance frameworks). Considering that policy can direct the educational process to a certain direction, it is important that it follows from learner needs. In order to do this, a comparison of the two was essential: both perspectives are presented so that the current situation shows if and what needs to change in these frameworks. The integration of both research designs will give a complete picture, in order to show the importance of inter-learner communication and collaborative learning for quality distance VET.

\section{The Research Process}

The present research consists of a qualitative and a quantitative part. For the qualitative part, previous research, the theoretical background and the research questions defined the field and initial themes/ key-words of the investigation. Through purposeful sampling, the texts were chosen among manuals of quality assurance frameworks, reports, proposals and other official texts from EU websites. The particular quality assurance frameworks were chosen on the basis that they can be applied to distance and e-learning VET, CPD courses and MOOCs. The initial themes/ key-words guided the choice of texts. After a first investigation, the initial themes were reduced and condensed to three (Robson, 2002):

- EU quality assurance organizations and frameworks,

- Inter-learner communication in quality criteria,

- Collaborative learning in quality criteria.

Content analysis started with the description and presentation of the background. Following the themes, text parts were assigned to a code, each belonging to one of the three themes.

For the quantitative sample survey, an online questionnaire (Google Forms) was created, as the particular population (adults who participate/ have participated within the last 5 years in a webbased VET, MOOC or CPD course) is familiar with new technologies. However, considering the fact that it was impossible to know the exact number of all these learners in Greece, nonprobability sampling was chosen as the most suitable (Creswell, 2012). As a result, the sample came from various sources: (a) two Centers for Vocational Education and Training (University of Ioannina and University of Patras, Greece), which offer web-based continuing VET and CPD courses and (b) volunteers found in the Hellenic Open University (Greece) forum and social media. The sample size was 157 participants.

As far as the questionnaire is concerned, it consisted of an introduction which informed participants about the aim of the research. All questions were closed-ended (multiple choice/ 
Likert scale). The responses-values for the scale were: 1 - Strongly disagree, 2 - Disagree, 3 - Neutral, 4 - Agree, 5 - Strongly agree.

The participants were sent via email an electronic link by their respective Centre. Anonymity was guaranteed and submitting the questionnaire signified their consent to participate. Simultaneously, the link was also available at the Hellenic Open University (Greece) forum and social media. Finally, the sample survey was conducted in March-April 2018, while the qualitative research in February 2018.

\section{Validity, Reliability and Significance of Results}

In the qualitative part of the research, reliability was a given, as all data were already public, in the official EU websites. The lack of interaction with the researcher contributed to the reliability of the sample survey, enhancing thus the objectivity of the process (Robson, 2002). Validity was guaranteed, as participants were asked to log in to their Gmail account, in order to ensure one submission per participant. As far as the content of the questionnaire is concerned, the definitions of inter-learner communication and collaborative learning were provided, so that everything would be understandable. Also, to ensure content validity, the questions-statements originated from the research questions and the theoretical background. Finally, a trial survey was conducted, with 5 participants, (not included in the final sample) in order to detect possible problems with clarity, structure and timing.

The sample was not representative of the population, so the generalization capacity was limited. On the other hand, the sample came from various backgrounds; consequently its characteristics are similar to those of the target population (Robson, 2002). Furthermore, wave analysis showed that the pattern of answers was consistent throughout the process (Creswell, 2012). These facts lead to the conclusion that generalization of the results is limited, but a deeper understanding of the issue in a general framework was accomplished (Robson, 2002).

\section{Results}

\section{Quality Assurance Frameworks}

The qualitative part investigated, through content analysis, the importance of inter-learner communication and collaborative learning for EU quality assurance frameworks. Firstly, we present the general context of the investigation field. Secondly, we focus on EU quality assurance organizations and frameworks, which include quality criteria related to collaborative learning and/ or inter-learner communication.

\section{The General Context}

The investigation of the relevant texts showed that the EU supports the learner's important role, not only in the learning process, but also generally in education. Consequently, quality assurance should take their opinion into consideration, when it comes to the creation of criteria (Official Journal of the EU, 2017). In the Yerevan Communiqué (2015), it was stated that learners should participate in the assessment processes, in order to improve quality.

Also, the EU believes that learners are the central component of the learning process, through their active participation and the use of learner-centred methods (Official Journal of the EU, 2014). Especially for distance VET, these methods prove to be invaluable, as they offer skills necessary for employability (Official Journal of the EU, 2014). Thus, they are closely connected to quality. This is the reason why they are both presented as important criteria in quality 
assurance frameworks. Special attention is given to collaborative learning, as its advantages are often analysed (EADTU, 2016).

\section{Quality Assurance Organizations and Frameworks}

The European policy for distance VET quality assurance is implemented by the relevant organizations, which create, in turn, criteria related to communication and collaborative learning. These frameworks are:

- 2005: E-xcellence. Its criteria are relevant for all types of distance courses and institutions (EADTU, 2016).

- 2010: ECB Check addresses both distance courses and institutions which offer vocational education.

- 2011: UNIQUe (European Universities Quality in e-Learning) aims to certify distance higher education and advanced vocational institutions through peer and self-assessment.

- 2014: OpenupEd Quality Label is designed exclusively for MOOCs.

- 2015: SEQUENT (Supporting Quality in e-Learning European Networks) addresses various types of web-based courses.

- 2015: MOOQ Quality Reference Framework aims at improving MOOC quality, while encouraging the use of innovative teaching methods.

- 2016: ReOpen addresses institutions that offer MOOCs and web-based VET courses.

\section{Inter-learner Communication and Collaborative Learning in Quality Criteria}

Two of the investigated quality assurance models - MOOQ QRF and ReOpen - do not include criteria as detailed as the others models do. However, they refer to the importance of course design, teaching methods and, specifically, inter-learner communication and participation. We present below, in alphabetical order, the rest of the quality assurance frameworks and their criteria that refer to inter-learner communication and collaborative learning.

In ECB Check (2012), we encounter a field of criteria entitled "Program/ Course Design"; the first subcategory "Learning Design and Methodology" encourages learner participation and communication, but only if they fulfil the course aims. The second subcategory includes criteria that support learner-centred teaching methods and collaboration, even though in the 2010 edition they were not presented as necessary. Most importantly, a whole subcategory is dedicated to collaborative learning, something which indicates the importance of this particular method. However, it is recognized that collaborative learning cannot be used in every course.

E-xcellence includes relevant criteria in almost every field (EADTU, 2016). The field of "Curriculum Design" encourages the creation of a learning community based on interaction, collaboration and social communication. Furthermore, collaborative learning is given special attention, as one of the three essential teaching methods; its advantages are analysed, but also its drawbacks (Ubachs, 2009). In the same field, inter-learner communication is considered vital (EADTU, 2016). The field of "Course Design" refers also to the necessity of inter-learner communication and collaborative learning through suitable assignments and communication media. Worth mentioning is the fact that E-xcellence Next was created, in order to add criteria concerning communication and collaboration through social media (EADTU, 2012). The field of "Course Delivery" includes criteria that encourage the use of virtual learning environments, suitable for communication and interactive teaching methods.

OpenupEd Quality Label uses the same fields as E-xcellence, but we encounter relevant criteria only in "Course Design". A learning community is presented as necessary. Inter-learner 
communication through suitable media and, finally, participation and relevant teaching methods are considered very important.

SEQUENT (2015) includes relevant criteria in two fields. "Design- Approval of Programs" refers generally to the necessity of learner participation and secondly, to the importance of collaborative activities, while recognizing at the same time possible difficulties. The field entitled "Student-centred Learning" includes criteria which guide the implementation of collaborative learning.

UNIQUe (2011) assesses the use of technology, which supports inter-learner communication and peer-assessment. Collaborative learning, however, is not presented as essential. Other fields that include relevant criteria are: policy of the institution (ECB Check, E-xcellence, OpenupEd Quality Label, SEQUENT, UNIQUe), technology and infrastructure (ECB Check, E-xcellence, SEQUENT, UNIQUe), learner support (E-xcellence, OpenupEd Quality Label, SEQUENT, UNIQUe) and teacher support (E-xcellence, SEQUENT, UNIQUe). Finally, the findings showed that all seven quality assurance frameworks include criteria related to inter-learner communication, whereas collaborative learning is included in five.

\section{Learner Views}

For the first part of the questionnaire, $50 \%$ of the participants answered that the duration of their current/ latest course was 1-3 months. $67 \%$ of the sample had experience with inter-learner communication in web-based VET, whereas $52.2 \%$ had experience with collaborative learning. We conclude that communication is implemented more often than collaborative learning.

The second part consisted of the following statements:

1. "Web-based inter-learner communication contributes to the quality of distance web-based VET'. Most participants agreed with this statement, as it had the highest mean value (3.99 on a scale of 1 to 5 ). Moreover the majority of answers were higher than the mean and only 6 participants (strongly) disagreed (Table 1).

2. "Web-based inter-learner communication should be included in the quality criteria of distance web-based VET". The second highest mean value was found for this statement (Table 2). The percentages of those who were neutral or disagreed were higher than those in the previous statement. However, the majority of the sample (strongly) agreed with the importance of inter-learner communication in quality assurance.

3. "Web-based inter-learner communication can be implemented in any web-based VET course". The mean value here was the second lowest of all statements. But still, most participants agreed or were neutral.

4. "Web-based collaborative learning contributes to the quality of distance web-based VET". More participants disagreed with this statement than with the respective statement for inter-learner communication. However, the majority agreed (70\%).

5. "Web-based collaborative learning should be included in the quality criteria of distance web-based VET". Comparing statements 2 and 5, the mean was also lower for collaborative learning. But, it is evident that most participants agreed.

6. "Web-based collaborative learning can be implemented in any web-based VET course". The percentage of those who (strongly) disagreed with this statement was the highest of all statements $(17.2 \%)$. Even though the mean was here the lowest, it is important that, again, most participants agreed. 
Finally, the sample was positively inclined towards all six statements. Also, it is evident that learners were slightly more positive towards inter-learner communication and less positive, as far as their implementation is concerned.

The Spearman correlation coefficient showed that there was significant correlation between statements for inter-learner communication and statements for collaborative learning $(r=0.268$ $\mathrm{p}=0.001)$. Some degree of correlation was also found between the need to include inter-learner communication/ collaborative learning in quality criteria and the ability to implement them in any course $(\mathrm{r}=0.335 \mathrm{p}=0.001 / \mathrm{r}=0.06 \mathrm{p}=0.001$ respectively). Moreover, the agreement with the need to include them in quality criteria seems to be related to the agreement with their contribution to quality. Something that explains the results is the participants' experience with distance communication and collaborative learning; contingency tables showed that learners with experience in web-based communication (collaborative learning respectively) agreed with its importance in quality criteria. Furthermore, it is evident that mostly participants in the age group 25-44 agreed with the need to include communication in the quality criteria of web-based VET. As far as the respective statement for collaborative learning is concerned, mostly participants above 45 agreed (Table 3). We conclude that age is related to opinions on this issue. Gender, on the other hand, did not influence the results and neither did course duration.

Table 1: Percentages for statements 1-6

\begin{tabular}{lccccc}
\hline Statements & $\begin{array}{c}\text { Strongly } \\
\text { disagree [\%] }\end{array}$ & Disagree [\%] & Neutral [\%] & Agree [\%] & $\begin{array}{c}\text { Strongly agree } \\
{[\%]}\end{array}$ \\
\hline 1 & 1.3 & 2.5 & 17.8 & 52.2 & 26.1 \\
2 & 0.6 & 7.6 & 21.7 & 47.1 & 22.9 \\
3 & 1.9 & 11.5 & 22.3 & 45.9 & 8.5 \\
4 & 1.3 & 9.6 & 19.1 & 44.6 & 25.5 \\
5 & 3.2 & 9.6 & 20.4 & 42 & 24.8 \\
6 & 1.9 & 15.3 & 26.1 & 36.3 & 20.4 \\
\hline
\end{tabular}

Table 2: Statistical analysis results for statements 1-6

\begin{tabular}{lcccc}
\hline Statements & Mean & Confidence interval 95\% & Std. deviation & Variance \\
\hline 1 & 3.99 & $3.86-4.12$ & .812 & .660 \\
2 & 3.84 & $3.70-3.98$ & .888 & .789 \\
3 & 3.67 & $3.52-3.82$ & .968 & .939 \\
4 & 3.83 & $3.67-3.97$ & .959 & .921 \\
5 & 3.75 & $3.59-3.92$ & 1.034 & 1.069 \\
6 & 3.57 & $3.41-3.74$ & 1.038 & 1.079 \\
\hline
\end{tabular}

Table 3: Contingency table for age and statement: "Web-based collaborative learning should be included in the quality criteria of distance web-based VET."

\begin{tabular}{lccccc}
\hline Age & $\begin{array}{c}\text { Strongly } \\
\text { disagree [\%] }\end{array}$ & Disagree [\%] & Neutral [\%] & Agree [\%] & $\begin{array}{c}\text { Strongly agree } \\
{[\%]}\end{array}$ \\
\hline $18-24$ & 0 & 0 & 33.3 & 66.7 & 0 \\
$25-29$ & 0 & 5.3 & 26.3 & 47.4 & 21.1 \\
$30-44$ & 3.1 & 12.4 & 22.7 & 39.2 & 22.7 \\
$45-54$ & 6.3 & 6.3 & 9.4 & 43.8 & 34.4 \\
$55-65$ & 0 & 0 & 20 & 60 & 20 \\
Over 65 & 0 & 0 & 0 & 0 & 100 \\
\hline Total & $3.2 \%$ & $9.6 \%$ & $20.4 \%$ & $42 \%$ & $24.8 \%$ \\
\hline
\end{tabular}




\section{Conclusion}

The quantitative sample survey showed that most participants agreed with all statements. As far as inter-learner communication is concerned, the majority of the participants believe that it contributes to quality and that it should be included in the quality criteria of web-based VET quality assurance frameworks. Slightly lower were the percentages for the ability to implement it in any course of this type. The rank was the same for the respective statements concerning collaborative learning. However, learners were more positive towards the importance of communication in quality assurance. Only half of the sample believes that it is possible to use collaborative learning under any circumstances. We conclude thus that they are both considered important in web-based VET, but opinion is divided, when it comes to their implementation.

Correlation between statements 1 and 2 (also 4 and 5) was expected, as contribution to quality justifies the need to assess the use of these particular methods. Furthermore, the fact that the results for statements 2 and 3 (also 5 and 6) were very close indicates that the ability to use them in any course is related to the ability and the need to include them in quality criteria. But, this need is somewhat lessened, if we consider that only half of the participants agree with the ability to use them (especially collaborative learning) under any circumstances. The results were also influenced by the lack of experience, firstly, with collaborative learning and secondly, with interlearner communication. This is probably the reason why some learners do not know the advantages of their use, so they consider them redundant. Also, this led them to believe that they cannot be implemented in every course of this type. The short duration of some courses or the lack of free time (work/ family obligations) may have affected their opinion.

The necessity for inter-learner communication in quality VET courses is also supported in previous research. The contribution of collaborative learning to quality and the need to include it in quality criteria was also found in previous studies, except for three (Creelman et al., 2014; Lenert \& Janes, 2017; Merisotis \& Phipps, 2000).

\section{EU Criteria and Learner Views}

In order to answer the second question, we compared the qualitative research findings with the results of the quantitative sample survey. Most participants believe that inter-learner communication and collaborative learning should be included in the quality criteria of web-based VET. But, collaborative learning was found slightly less important and more difficult to implement.

The qualitative part of the research indicated the learners' crucial role in EU quality assurance. Specifically, special attention is given by European organizations to inter-learner communication and collaborative learning. It was found that inter-learner communication is included in all the investigated EU quality assurance frameworks. Collaborative learning is not included in two (MOOQ QRF, ReOpen) out of seven frameworks (29\%). However, these two frameworks did not present detailed criteria, so we could not draw definite conclusions. Although some frameworks (E-xcellence, SEQUENT) focus extensively on collaborative learning, analysing its advantages, others admit its difficulties or present it as not essential.

The important place of inter-learner communication and collaborative learning in EU quality assurance frameworks is in agreement with the theories of social constructivism and transactional distance. Their presence in most of the investigated frameworks is underlined in previous 
research too (Kear et al., 2012; Ossiannilsson \& Landgren, 2012; Peres et al., 2014; Rosewell \& Jansen, 2014).

Comparing the above conclusions, EU policy agrees with learner views, as both admit the importance of inter-learner communication and collaborative learning. But, all the relevant EU quality assurance organizations consider inter-learner communication essential for quality, whereas only $70 \%$ of the learners did. This percentage could be lower, if we consider that only half of the sample believes that it can be implemented in any course. As far as collaborative learning is concerned, $71 \%$ of the investigated EU quality assurance models include it in quality criteria and, at the same time, $66 \%$ of the learners believe in its inclusion. Thus, for collaborative learning, there is an absolute agreement between EU policy and learners. This is justified by the fact that, according to the results, both consider this method difficult to implement. Participants were probably influenced by the scarce use of collaborative learning in Greek distance education. In practice, learners may find communication and collaborative learning difficult to implement, due to the lack of guidance and support. On the other hand, lack of free time and the short duration/ workload of CPD courses could explain the results.

\section{Inter-Learner Communication and Collaborative Learning}

The statistical analysis showed that learners agreed more with the statements concerning interlearner communication. Even though the majority was positive towards both, collaborative learning had lower percentages in every statement, something which shows that it is less important in quality assurance than inter-learner communication. This is justified by the fact that only half of the sample thinks that it is possible to implement collaborative learning under any circumstances. Learners could have been influenced by Greek distance education, which usually avoids collaborative learning. Moreover, it was found that the sample had more experience with inter-learner communication than with collaborative learning.

The statistical analysis indicated significant correlation between the statements for inter-learner communication and the respective statements for collaborative learning. This shows that they are related, considering additionally the fact that communication is a fundamental characteristic of collaborative learning (Moore, 2013). The preference for inter-learner communication, though, could be justified by the complexity of collaborative processes. Learners and EU organizations seem to consider inter-learner communication much simpler, as the difficulties of collaborative learning implementation are often analysed in the investigated EU texts. For instance, most adults- due to work and family obligations- do not have the time to collaborate.

Wang (2014) came to the conclusion that only communication is not enough. Others found that, compared to communication, collaborative learning is redundant or it was not researched at all (Claus \& Dooley, 2005; Creelman et al., 2014; Inglis, 2005; Jacobs \& DeWet, 2013; Merisotis \& Phipps, 2000; Mystakidis et al., 2017). In Alexander and Golja (2007) and Ehlers (2004), both were equally important, as collaborative learning is considered part of the communication spectrum.

Finally, we draw the conclusion that inter-learner communication and collaborative learning should be included in the quality criteria of web-based VET. However, their implementation (especially of collaborative learning) in every course is not widely accepted, especially by learners who do not have time to communicate. Although EU quality assurance frameworks were deemed suitable in Greece, some of them present inter-learner communication and collaboration as obligatory. A common quality assurance system for web-based VET should encourage and also assist with their use through guidelines, but it is not realistic to demand their implementation in every course. 


\section{References}

1. Alexander, S., \& Golja, T. (2007). Using students' experiences to derive quality in an e-learning system: an institution's perspective. Educational Technology \& Society, 10(2), 17-33.

2. Baldwin, S., \& Trespalacios, J. (2017). Evaluation instruments and good practices in online education. Online Learning, 21(2). Retrieved from https://olj.onlinelearningconsortium.org/index.php/olj/article/view/913

3. Claus, E., \& Dooley, K. (2005). Quality in distance education: A preliminary review of the literature. Retrieved from http://files.eric.ed.gov/fulltext/ED492449.pdf

4. Collardyn, D., \& Bjornavold, J. (2004). Validation of formal, non-formal and informal learning: Policy and practices in EU member states. European Journal of Education, 39(1), 69-89.

5. Creelman, A., Ehlers, U., \& Ossiannilsson, E. (2014). Perspectives on MOOC quality - An account of the EFQUEL MOOC Quality Project. The International Journal for Innovation and Quality in Learning, 3, 78-87.

6. Creswell, J. W. (2012). Educational research: planning, conducting and evaluating quantitative and qualitative research (4th ed.). Boston: Pearson.

7. DeGennaro, D. (2010). Grounded in theory: Immersing pre-service teachers in technologymediated learning. Contemporary Issues in Technology and Teacher Education, 10(3), 338-359.

8. EADTU (2012). E-xcellence Next. Quality assessment for e-learning: a benchmarking approach. Maastricht: EADTU.

9. EADTU (2016). E-xcellence. Quality assessment for e-learning: a benchmarking approach. Maastricht: EADTU.

10. ECB Check (2012). Open ECB Check quality criteria for programmes. Retrieved from http://www.ecb-check.net/downloads/

11. Ehlers, U. (2004). Quality in e-learning from a learner's perspective. European Journal of Open, Distance and E-Learning, 2004(1). Retrieved from

http:/ / www.eurodl.org/?p=archives\&sp $=$ full\&article $=101$

12. Ellis, R., \& Calvo, R. (2007). Minimum indicators to assure quality of LMS-supported blended learning. Educational Technology \& Society, 10(2), 60-70.

13. European Commission (2018). Proposal for a council recommendation on promoting common values, inclusive education, and the European dimension of teaching, COM (2018) 023 final.

14. Garrison, R. (2000). Quality and access in distance education: Theoretical considerations. In D. Keegan (Ed.), Theoretical principles of distance education (pp. 9-21). New York: Routledge.

15. Gunawardena, C., \& McIsaak, M. (2004). Distance education. In D.H. Jonassen (Ed.), Handbook of research for educational communities and technology (pp.355-395). London: Lawrence Erlbaum Associates Publishers.

16. Inglis, A. (2005). Quality improvement, quality assurance and benchmarking: Comparing two frameworks for managing quality processes in open and distance learning. The International Review of Research in Open and Distributed Learning, 6(1).

17. Jacobs, L., \& DeWet, C. (2013). Evaluation of the Vocational Education Orientation Programme (VEOP) at a University in South Africa. The International Review of Research in Open and Distributed Learning, 14(4), 68-89. 
18. Jung, I. (2012). Asian learners' perception of quality in distance education and gender differences. The International Review in Open and Distributed Learning, 13(2), 1-25.

19. Kear, K., Rosewell, J., \& Keith, W. (2012). Social networking and open educational resources: Updating quality assurance for e-learning excellence. Paper presented at the EADTU $25^{\text {th }}$ Anniversary Conference "The Role of Open and Flexible Education in European Higher Education Systems for 2020: New Models, New Markets, New Media”, 27-28 September 2012, Paphos, Cyprus.

20. Kidd, T., \& Song, H. (2007). A case study of the adult learners' perception of instructional quality in web-based online courses. In Y. Inoue (Ed.), Online education for lifelong learning (pp. 271-291). Hershey: Information Science Publishing.

21. Lenert, K., \& Janes, D. (2017). The incorporation of quality attributes into online course design in higher education. International Journal of E-Learning and Distance Education, 32(1). Retrieved from http://www.ijede.ca/index.php/jde/article/view/987/1660

22. Letherby, G., \& Bywaters, P. (2007). Extending social research: why? In G. Letherby \& P. Bywaters (Eds.), Extending social research. Application, implementation and publication (pp. 19-36). Glasgow: Open University Press, McGraw Hill.

23. Mayring, P. (2000). Qualitative content analysis. Forum: Qualitative Social Research, 1(2). Retrieved from http://www.qualitative-research.net/index.php/fqs/article/view/1089/2386

24. Merisotis, J., \& Phipps, R. (2000). Quality on the line. Benchmarks for success in internet based distance education. Washington: The Institute for Higher Education Policy.

25. MOOQ. International organizations supporting the quality initiative MOOQ. Retrieved from http://www.mooc-quality.eu/survey

26. Moore, M. G. (2000). Transactional distance. In D. Keegan (Ed.), Theoretical principles of distance education (pp. 22-38). New York: Routledge.

27. Moore, M. G. (2013). The theory of transactional distance. In M.G. Moore (Ed.), Handbook of distance education (pp. 66-85). New York: Routledge.

28. Mystakidis, S., Kostopoulos, K., \& Amanatidis, E. (2017). Preconditions for quality distance vocational training: The case of the Patras University Center for Vocational Education and Training. Paper presented at the $9^{\text {th }}$ International Conference in Open \& Distance Learning, November 2017, Athens, Greece.

29. Official Journal of the European Union (2014). European Parliament resolution of 15 April 2014 on new technologies and open educational resources, 2017/C 443/05.

30. Official Journal of the European Union (2017). Conclusions of the Council and of the Representatives of the Governments of the Member States on inclusion in diversity to achieve a high quality education for all, 2017/C 62/02.

31. OpenupEd. OpenupEd Quality Label. Retrieved from http://www.openuped.eu/qualitylabel/

32. Ossiannilsson, E. (2012). Quality enhancement on e-learning. Campus-wide Information Systems, 29(4), 312-323.

33. Ossiannilsson, E., \& Landgren, L. (2012). Quality in e-learning - A conceptual framework based on experiences from three international benchmarking projects. Journal of Computer Assisted Learning, 28(1), 42-51. 
34. Peres, P., Lima, L., \& Lima, V. (2014). B-learning quality: Dimensions, criteria and pedagogical approach. European Journal of Open, Distance and E-learning, 17(1), 56-75.

35. Read, T., \& Rodrigo, C. (2014). Toward a quality model for UNED MOOCs. eLearning Papers, $37,43-50$.

36. Reis, R., Gomes, T., \& Reis, B. (2008). Learning management systems in vocational schools. WSEAS Transactions on Advances in Engineering Education, 8(5), 580-590.

37. ReOpen. About the project. Retrieved from http://www.reopen.eu/about-project/

38. Robson, C. (2002). Real world research. Oxford: Blackwell Publishers.

39. Rogers, A. (2002). Teaching adults. Berkshire: Open University Press.

40. Rosewell, J., \& Jansen, D. (2014). The OpenupEd Quality Label: Benchmarks for MOOCs. The International Journal for Innovation and Quality in Learning, 3, 88-100.

41. SEQUENT (2015). Supporting Quality in e-learning European Networks - SEQUENT. Retrieved from http://www.enqa.eu/index.php/supporting-quality-in-e-learning-european-networkssequent/

42. Simonson, M., Smaldino, S., \& Zvacek, S. (2015). Teaching and learning at a distance: Foundations of distance education. Charlotte: Information Age Publishing.

43. Stacey, E. (1999). Collaborative learning in an online environment. Journal of Distance Education, 14(2), 14-33.

44. Ubachs, G. (2009). E-xcellence. Quality assessment for e-learning: a benchmarking approach. Heerlen: EADTU.

45. UNIQUe (2011). European Universities Quality in e-Learning. Information package. Brussels: EFQUEL.

46. Vygotsky, L. (1978). Interaction between learning and development. In Gaurain \& Cole (Eds.), Readings on the development of children (pp.34-40). New York: Scientific American Books.

47. Wang, Y. C. (2014). Using wikis to facilitate interaction and collaboration among EFL learners: A social constructivist approach to language teaching. System, 42(1), 383-390. https://doi.org/10.1016/j.system.2014.01.007

48. Ward, M., Peters, G., \& Shelley, K. (2010). Student and faculty perceptions of the quality of online learning experiences. The International Review of Research in Open and Distributed Learning, 11(3), 57-77.

49. Williams, K. (2015). SEQUENT. Deliverable 4, Handbook for quality in e-learning procedures.

Retrieved from https://www.sequent-

network.eu/images/Guidelines/Sequent_Handbook_for_Quality_in_e-

learning_procedures.pdf

50. Yeung, D. (2001). Toward an effective quality assurance model of web-based learning: The perspective of academic staff. Online Journal of Distance Learning Administration, 4(4). Retrieved from https://www.westga.edu/ distance/ojdla/winter44/yeung44.html

51. Yerevan Communiqué (2015). EHEA Ministerial Conference, Yerevan Communiqué 2015.

Retrieved from

http://www.ehea.info/media.ehea.info/file/2015_Yerevan/70/7/YerevanCommuniqueFina 1_613707.pdf 
Inter-Learner Communication and Collaborative Learning as Quality Criteria of Distance Vocational Education and Training Anastasia Batsila

52. Zawacki-Richter, O., Baker, E., \& Vogt, S. (2009). Review of distance education research (2000 to 2008): Analysis of research areas, methods and authorship patterns. International Review of Research in Open and Distance Learning, 10(6), 21-50.

\section{Acknowledgement}

The author would like to thank Dr. Ioanna Tsarpa for her valuable guidance during the research. 